\title{
Turkish Version of the Dutch Eating Behaviour Questionnaire: In Evaluation of Eating Behaviour among a Group of Turkish University Student
}

\author{
Lale Sariye Akan, Ayşe Özfer Özçelik and Metin Saip Sürücüoğlu \\ Ankara University Faculty of Health Sciences, Department of Nutrition and Dietetics, Cebeci 06260, Turkey
}

\begin{abstract}
Objective: This study aims at examining eating behaviours according to the Dutch Eating Behaviour Questionnaire (DEBQ), among a population of normal-weight university students. Methods: The study was conducted among Ankara University students. The questionnaire was administered to 500 subjects. The participants were given a questionnaire form. A reliability test was performed to determine the extent the 33-item questionnaire can measure eating behaviors of individuals. Items 31, "Can you resist eating delicious food?", and 32, "Do you eat more than usual when you see others eating (do you eat even if it is not meal time)?" were removed from the questionnaire since their factor loading values were below 0.30. "Varimax Factor Analysis" was performed to determine if the survey questions used in this research have the same structure. Results: The analysis resulted in three factors. This study demonstrated the factorial validity and reliability of its Dutch version.
\end{abstract}

Key words: Dutch Eating Behavior Questionnaire (DEBQ), external eating, emotional eating, restrained eating.

\section{Introduction}

Research studies on eating behaviour are necessary to increase our understanding of the aetiology of obesity and contribute to improve therapeutic programs. These investigations require valid and reliable scales to assess and quantify factors associated with eating behaviour. The development of questionnaires usually relies on underlying theories of eating. The Dutch Eating Behaviour Questionnaire (DEBQ) [1-3] was originally elaborated in order to test the relevance of suchtheories in understanding the development and maintenance of human obesity. The first one, the so called "psychosomatic theory" [3] emphasizes the role of "emotional eating" in the aetiology of obesity. The second one, the "external theory" developed by Schachter and colleagues (1968), refers to eating in response to food-related stimuli, regardless of the internal state of hunger or satiety [4]. The third one, the

Corresponding author: Lale Sariye Akan, PhD, research fields: food and nutrition, nutrition culture. E-mail: laleakan@yahoo.co.uk. theory of "restrained eating" [5], reflects the degree of conscious food restriction, carrying the imminent risk of disinhibition. During youth, feeding needs are adequate and appropriate for the requirements of the body. However, studies conducted in our country reveal that university students have eating disorders, not being able to eat an adequate and balanced diet. That university students have right eating habits is of social importance on accounts of their own health and this group being a role model $[6,7]$. During this period, eating behaviors of the young changed $[8,9]$. This study aims at examining eating behaviours according to the Dutch Eating Behavior Questionnaire (DEBQ), among a population of normal-weight university students.

\section{Material and Methods}

This study was designed to determine eating behaviors of university students with normal body weight (those with BMI values of $18.5-24.9 \mathrm{~kg} / \mathrm{m}^{2}$ were included in the study). The research subjects consisted of 500 volunteer students who study at 
various universities in Ankara. The Dutch Eating Behaviour Questionnaire (DEBQ) was used to determine eating behaviors of the students $[1,2,10]$.

\subsection{The Dutch Eating Behavior Questionnaire} (DEBQ)

In its original version, the $\mathrm{DEBQ}$ is a 33-item self-rating questionnaire. All items have the same response format: never (1), seldom (2), sometimes (3), often (4) and very often (5). Restrained and external eatings are both assessed with a 10-item scale; emotional eating may either be assessed with a 9-item scale and a 4-item scale, referring to clearly defined and diffuse emotions, respectively, or with a combined 13-item scale. The questionnaire was collected by interview. An average of ten minutes was necessary to fill in the form.

\subsection{Reliability}

As the questionnaire was completed once, reliability was assessed by internal consistency. Coefficients used were Cronbach's alpha coefficients, calculated separately for each sub-scale. Mean alpha was calculated to be $81.98 \pm 16.71$.

\subsection{Statistical Analysis}

Numerical and percentage tables were constructed for general information. Varimax Factor Analysis and reliability tests were performed.

\section{Results}

3.1 Characteristics of the Sample
The study included a total of 500 subjects (260 female, 240 male). Mean age was 20.34 2.01 years for

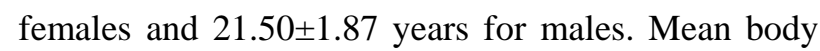
mass index was found to be $23.02 \pm 2.05 \mathrm{~kg} / \mathrm{m}^{2}$ for females and $24.08 \pm 2.91 \mathrm{~kg} / \mathrm{m}^{2}$ for males. Age and BMI (means and standard deviations, SD) are presented in Table $1.16 .2 \%$ of the female students included in the research eat 2 times a day, 35.0\% 3 times, 37.7\% 4 times, and $11.2 \% 5$ times or more. For male students, it is $10.0 \%, 30.4 \%, 45.8 \%$, and $13.8 \%$ (for $2,3,4$, and 5 or more meals per day, respectively). The meal that is skipped most is breakfast, at a rate of $29.2 \%$ for females and $25.0 \%$ for males. It is followed by lunch (Females: 12.3\%, Males: 7.1\%) and dinner (Females: 7.7\%, Males: 5.4\%). Students skip breakfast because they don't have time (Females: 44.2\%, Males: 43.8\%). Females said they skip lunch to stay thin (to avoid a big belly) (20.4\%) and males because they don't have appetite (17.9\%). Since most of the students don't skip dinner, the rate of students who skip it because they don't have appetite is the highest (F: 11.2\%, M: 7.9\%).

\subsection{Varimax Rotated Factor Matrix}

After the factor analysis was applied to the data (5-, 4-, and 3-factor solutions), it was found that the best interpretable matrix is the three-factor solution. The factor loadings found in this analysis are presented in Table II. The three factors account for 40.6\%, 47.3\%, and $43.5 \%$ of the variance, respectively. Factor 1 corresponds to all items in the emotional eating scale (loadings above 0.36). Factor 2 is based on all items in the restrained eating scale. And factor 3 corresponds to all items in the eating scale (except for items 31 and 32) (Table 2).

Table 1 Means and standard deviations for students' weight, height, and body mass index.

\begin{tabular}{|c|c|c|c|c|c|c|c|}
\hline \multirow{2}{*}{ Gender } & $\mathbf{n}$ & \multicolumn{2}{|c|}{ Weight (kg) } & \multicolumn{2}{c|}{ Height (cm) } & \multicolumn{2}{c|}{ BMI (kg/m $\mathbf{~}^{\mathbf{2}}$} \\
\cline { 2 - 8 } & & $\overline{\mathrm{X}}$ & $\mathrm{S}$ & $\overline{\mathrm{X}}$ & $\mathrm{S}$ & $\overline{\mathrm{X}}$ & $\mathrm{S}$ \\
\hline Female & 260 & 56,9846 & 1,13274 & 163,8038 & 3,30956 & 23,0294 & 2,05924 \\
\hline Male & 240 & 75,1583 & 2,77732 & 176,5250 & 4,01279 & 24,0853 & 2,91656 \\
\hline Total & 500 & 65,7080 & 3,23249 & 169,9100 & 2,44088 & 23,5362 & 2,62628 \\
\hline
\end{tabular}


Table 2 Varimax Rotated Factor Matrix (three-factor solution) on the 33 items, in the Turkish version of the DEBQ for the total sample.

\begin{tabular}{|c|c|c|c|}
\hline & Factor I & Factor 2 & Facfor 3 \\
\hline Eigenvalue & 4.06 & 6.15 & 3.48 \\
\hline Percent of variance & $40.6 \%$ & $47.3 \%$ & $43.5 \%$ \\
\hline \multicolumn{4}{|l|}{ Restrained eating } \\
\hline 1. If you have put on weight, do you eat less than yocl usually do? & ,757 & 064 &,- 193 \\
\hline 2. Do you try to eat less at mealtimes than you would like to eat? & ,361 & ,057 & ,004 \\
\hline $\begin{array}{l}\text { 3. How often do you refuse food or drink offered because you are concerned about your } \\
\text { weight? }\end{array}$ & ,642 & ,066 &,- 169 \\
\hline 4. Do you watch exactly what you eat? &, 537 & 019 &,- 071 \\
\hline 5. Do you deliberately eat foods that are slimming? & ,659 & ,200 &,- 134 \\
\hline 6. When you have eaten too much, do you eat less than usual the following days? & ,733 & ,101 &,- 106 \\
\hline 7. Do you deliberately eat less in order not be become heavier? & ,773 & 026 &,- 132 \\
\hline 8. How often do you try not to eat between meals because you are watching your weight? & ,537 & 044 &,- 006 \\
\hline 9. How often in the evening do you try not to eat because you are watching your weight? & ,510 & 048 & ,001 \\
\hline 10. Do you take into account your weight with what you eat? & ,615 & 152 & 028 \\
\hline \multicolumn{4}{|l|}{ Emotional eating } \\
\hline 11. Do you have the desire to eat when you are irritated? & ,177 & ,649 & 083 \\
\hline 12. Do you have a desire to eat when you have nothing to do? & ,176 & ,417 & ,263 \\
\hline 13. Do you have a desire to eat when you are depressed or discouraged? &,- 009 & ,455 &,- 002 \\
\hline 14. Do you have a desire to eat when you are feeling lonely? & ,074 & ,705 & ,199 \\
\hline 15. Do you have a desire to eat when somebody lets you down? & 167 & ,777 & ,103 \\
\hline 16. Do you have a desire to eat when you are cross? & 074 & ,751 & 079 \\
\hline 17. Do you have a desire to eat when you are approaching something unpleasant to happen? &, 119 & ,752 &,- 018 \\
\hline 18. Do you get the desire to eat when you are anxious, worried or tense? & 054 & ,713 & ,009 \\
\hline $\begin{array}{l}\text { 19. Do you have a desire to eat when things are going against you or when things have } \\
\text { gone wrong? }\end{array}$ & ,059 & ,793 & ,034 \\
\hline 20. Do you have a desire to eat when you are frightened? &,- 048 &, 561 &,- 018 \\
\hline 21. Do you have a desire to eat when you are disappointed? & ,172 & ,734 &, 047 \\
\hline 22. Do you have a desire to eat when you are emotionally upset? &, 117 & ,615 &, 176 \\
\hline 23. Do you have a desire to eat when you are bored or retless? & ,040 & ,739 &, 090 \\
\hline \multicolumn{4}{|l|}{ External eating } \\
\hline 24. If food tastes good to you, do you eat more than usual? &, 014 &,- 063 & ,628 \\
\hline 25. If food smells and looks good, do you eat more than usual? &,- 091 &, 081 & ,745 \\
\hline 26. If you see or smell something delicious, do you have a desire to eat it? &,- 116 &, 000 & ,616 \\
\hline 27. If you have something delicious to eat, do you eat it straight away? &,- 095 & 108 & ,661 \\
\hline 28. If you walk past the baker, do you have the desire to buy something delicious? &,- 106 & 077 & ,717 \\
\hline $\begin{array}{l}\text { 29. If you walk past a snackbar or a cafe, do you have the desire to buy something } \\
\text { delicious? }\end{array}$ &,- 062 & ,112 & ,725 \\
\hline 30. If you see others eating, do you also have the desire to eat? &,- 041 & ,190 & ,549 \\
\hline 33. When preparing a meal, are you inclined to eat something? &,- 129 & ,083 & ,491 \\
\hline
\end{tabular}




\section{Discussion}

Strong similarities were found between the Dutch and French versions of the DEBQ. The validity of the high acceptability and the general comprehension of the items were good. The presence of three factors ("emotional", "restrained", and "external eating") indicates a good factorial validity. This analysis has shown similarities to our study as well. However, only normal-weight individuals were used in our study. The three factors individualized with the French version are close to the Dutch version. The same three factors were also found by the French version of the DEBQ presents a good reliability, which is equivalent to the original Dutch version of the questionnaire. There is a good reliability in our study too (except for items 31 and 32).

This study demonstrates the factorial validity and reliability in its French version, by replicating the factor structure of the DEBQ and founding a high internal consistency. Applied to larger groups in our country, the DEBQ should be a useful tool to identify personality factors related to individual eating patterns implicated in eating disorders.

\section{References}

[1] T. Van Strien, J. E. R. Frijters, G. P. A. Bergers and P. B. Defares, The Dutch Eating Behavior Questionnaire for assessment of restrained, emotional and external eating behavior, Int J Eat Disorder 5 (1986) 295-315.

[2] T. Strien, J. E. R. Frijters, G. P. A. Bergers and P. B. Defares, The Dutch Eating Behavior Questionnaire (DEBQ) for assessment of restrained, emotional, and external eating behavior, Int. J. Eating Disorders 3 (2006) $12-15$.

[3] H. I. Kaplan and H. S. Kaplan, The psychosomatic concept of obesity, J Nerv Ment Dis. 125 (2007) 181-201.

[4] S. Schachter, R. Goldman and A. Gordon, Effects of fear, food deprivation and obesity on eating, J Person Sot Psychof. 92 (1968) 210-215.

[5] C. P. Herman and D. Mack, Restrained and unrestrained eating, J Personality 43 (1975) 64740.

[6] J. Tashiro, Exploring health promoting lifestyle behaviors of Japanese college women: perceptions, practices, and issues, Health Care Women International 23 (2002) (1) 59-70.

[7] P. Tokgöz, M. Ertem, F. Çelik, Ş. Gökçe, G. Saka and R. Hatunoğlu, Üniversite öğrencilerinin beslenme alışkanlıklarının saptanmasına ilişkin bir araştırma, Beslenme ve Diyet Dergisi. 24 (1995) (2) 229-238.

[8] D. O. Nnanyelugo and E. C. Okeke, Food habits and nutrient intakes of Nigerian University students in traditional halls of residence, J Am Coll Nutr. 6 (1987) (5) 369-374.

[9] T. A. Wadden and A. J. Stunkard, Social and psychological consequences of obesity, Ann. Intern Med. 1995 (1995) (103) 1062-1067.

[10] A. Lluch, J. P. Kahn, A. Stricker-Krongrad, O. Ziegler, O. Drouin and L. Mejean, Internal validation of a Fench version of the Dutch Eating Behaviour Ouestionnaire, Eur Psychiatry 11 (2006) 198-203. 